\title{
Improved Carbamazepine Bioremoval Using A Rotating Basket Contactor Reactor Under Non-Sterile Conditions
}

\author{
Xueqing Li, Renata Alves de Toledo, and Hojae Shim
}

\begin{abstract}
A rotating basket contactor reactor immobilized with Phanerochaete chrysosporium on polyurethane foam cubes $(1.0 \times 1.0$ $\times 1.0 \mathrm{~cm}^{3}$ ) was developed to treat a synthetic wastewater containing $1,000 \mu \mathrm{g} / \mathrm{L}$ of carbamazepine. The reactor was continuously operated for 160 days under non-sterile condition. The removal efficiency for carbamazepine exceeded $90 \%$ after one month of fungal adaptation through the addition of external carbon source in the influent. Nutrients and oxygen were effectively transferred to fungi, which contributed to the excellent treatment performances of the bioreactor in the long-term continuous operation. This study would provide an effective and feasible way to use the white-rot fungus bioreactor for the removal of carbamazepine under non-sterile conditions.
\end{abstract}

Keywords-Carbamazepine, Intermittent operation mode, Rotating Basket Contactor Reactor, White-rot fungus.

\section{INTRODUCTION}

$\mathrm{C}$ ARBAMAZEPINE is an antiepileptic drug known by its recalcitrant nature [1-3] and consequently the lower removal efficiency (usually $<10 \%$ ) through the conventional activated sludge process [4]. It has been detected in various water bodies worldwide $[5,6]$. The existing processes capable of more effectively removing this compound mainly include ozonation, advanced oxidation processes, membrane separation, and activated carbon sorption [7-9]. However, the disadvantages of these technologies include the high operational costs and the formation of toxic intermediates or by-products. The biological process able to degrade the contaminant at a low cost has gained an increasing attention as a potent technology to remove the recalcitrant pharmaceutically active compounds.

White-rot fungus has been reported the only microorganism to effectively degrade carbamazepine $[10,11]$. However, most studies have been conducted under sterile conditions $[11,12]$. Moreover, the removal efficiency for this compound varied, from around $20 \%$ to higher than $90 \%$ [12, 13]. It should also be noted that even though a satisfactory performance has been achieved under non-sterile conditions, it was still difficult to maintain the performance for a long-term due to the bacterial contamination [14]. Rodarte-Morales et al. [12] obtained a removal efficiency as high as $93 \%$ for carbamazepine through a stirred tank reactor operated with free pellets of $P$.

Xueqing Li, Renata Alves de Toledo, and Hojae Shim are with the Department of Civil and Environmental Engineering, Faculty of Science and Technology, University of Macau, Avenida da Universidade, Taipa, Macau SAR, China chrysosporium under the continuous feed mode. However, the stable removal performance was maintained for 55 days and then decreased subsequently.

It is important to keep the activity and dominance of white-rot fungi over the bacterial overgrowth in order to maintain a long-term stable performance in the bioreactor. The important role of the external carbon source in the $P$. chrysosporium growth was confirmed by Kirk et al. [15]. They reported $P$. chrysosporium would neither grow nor degrade the lignin if no co-substrate (glucose or cellulose) added due to the low energy produced from the lignin biodegradation. As an aerobic microorganism, oxygen is crucial to the $P$. chrysosporium growth and development [16]. Leisola et al. [17] indicated that the partial oxygen limitation was the main reason for the slow and incomplete degradation of lignin by $P$. chrysosporium in non-agitated cultures.

The immobilization of white-rot fungi shows many advantages. The immobilized cultures tend to have a higher level of activity and are more resilient to the environmental perturbations such as $\mathrm{pH}$ or the exposure to toxic chemicals concentrations than the suspended cultures. The cell immobilization would reduce the apparent broth viscosity and make the rheological features more favorable for oxygen supply and mass transfer. Another advantage of cell immobilization is the reduction in the protease activity and the contamination risk [18].

The objective of this study is the establishment of a proper bioreactor configuration for the white-rot fungus growth under non-sterile conditions to further improve the removal of carbamazepine from a synthetic wastewater by enhancing the enzyme production.

\section{MATERIALS AND METHODS}

\section{A. Microorganism}

The white-rot fungus strain P. chrysosporium BKM-F-1767 was purchased from Guangdong Institute of Microbiology (China). The strain was transferred and subcultured onto a fresh PDA medium plate which consisted of $20 \mathrm{~g}$ glucose, $3 \mathrm{~g}$ $\mathrm{KH}_{2} \mathrm{PO}_{4}, 1.5 \mathrm{~g} \mathrm{MgSO}_{4}, 0.1 \mathrm{~g} \mathrm{CaCl}_{2}, 8 \mathrm{mg}$ thiamine, and $20 \mathrm{~g}$ agar in $1 \mathrm{~L}$ of $20 \%$ potato extract. The spores formed on the plate were scraped and prepared into a spore suspension with the concentration of $15 \times 10^{6} / \mathrm{mL}$ through the dilution. The spore suspension was stored in a refrigerator until use. 


\section{B. Chemicals}

Carbamazepine was purchased from Sigma-Aldrich (USA). The stock solution $(1.0 \mathrm{~g} / \mathrm{L})$ was prepared in methanol and kept at $4{ }^{\circ} \mathrm{C}$. All other chemicals used were of analytical grades.

\section{Carrier}

The polyurethane foam cubes (density, $74 \mathrm{~kg} / \mathrm{m}^{3}$ ) were used as the support for the $P$. chrysosporium immobilization. Polyurethane foam is considered an excellent support for the microbial immobilization due to its stability, mechanical strength, and high porosity for the immobilized cells [19].

\section{Rotating Basket Contactor Reactor}

Twelve baskets made of stainless steel mesh were uniformly distributed on a stainless disk (diameter, $14 \mathrm{~cm}$ ). The size of each basket was $3.5 \mathrm{~cm} \times 6.0 \mathrm{~cm} \times 4.0 \mathrm{~cm}$, filled with $1.0 \times 1.0$ $\times 1.0 \mathrm{~cm}^{3}$ polyurethane foam cubes immobilized with $P$. chrysosporium. An electric shaft rotated at $0.44 \mathrm{~m} / \mathrm{min}$ drove the disk. The run and stop time of the disc could be controlled through the shaft connected to an intermittent switch (GB-60, Jinlong Electrical, China). The synthetic wastewater was pumped from an inlet tank into a reaction tank and the treated effluent was discharged into another storage tank.

There were two phases involved in the whole operational period, the comparison study during the first ten days and the continuous experiment during the remaining period. For the comparison study, both run time and stop time of the bioreactor were set at 5 min during the first five days, while the stop time was extended to $15 \mathrm{~min}$ during the next five days. The removal performances were compared between the two operational modes. Based on the optimized results, the continuous experiment in the second phase was carried out for around 160 days with the synthetic wastewater continuously fed into the bioreactor. The feeding glucose concentration was cut from 10 to $5 \mathrm{~g} / \mathrm{L}$ on Day 74 and further cut from 2.5 to $1 \mathrm{~g} / \mathrm{L}$ on Day 118. The hydraulic retention time (HRT) was three days. No biomass was replenished or discharged from the reactor during the continuous operation.

\section{E. Analyses}

The concentration of carbamazepine was measured using a Dionex UltiMate 3000 HPLC system (Thermo Scientific, USA) equipped with a Acclaim ${ }^{\mathrm{TM}} \mathrm{C} 30$ reversed-phase HPLC column $(5 \mu \mathrm{m}, 4.6 \times 150 \mathrm{~mm})$ and a Dionex UltiMate 3000 diode array detector. The column temperature, detection wavelength, and injection volume were set at $30^{\circ} \mathrm{C}, 220 \mathrm{~nm}$, and $100 \mu \mathrm{L}$, respectively. The mobile phase was composed of acetonitrile and deionized water buffered with $50 \mathrm{mM}$ phosphate solution $(\mathrm{pH} 3.0)$ at 3:7 $(\mathrm{v} / \mathrm{v})$ and the eluent went through the column at the flow rate of $0.5 \mathrm{~mL} / \mathrm{min}$.

The manganese peroxide (MnP) activity was measured, according to the method described by Tien and Kirk [20] with modifications. Ten milliliters of the reaction system contained $0.4 \mathrm{mM}$ guaiacol, $0.2 \mathrm{mM} \mathrm{MnSO}_{4}$, and $0.1 \mathrm{mM} \mathrm{H}_{2} \mathrm{O}_{2}$ added to trigger the chemical reaction. The $\mathrm{pH}$ value in this system was adjusted to 4.5 , buffered with $50 \mathrm{mM}$ sodium succinate. After the reaction at $30^{\circ} \mathrm{C}$ for $5 \mathrm{~min}$, the changes in optical density
(OD) were recorded at $465 \mathrm{~nm}$ using a spectrophotometer (UV Mini-1240 Spectrophotometer, Shimadzu, Japan). One unit (U) of the MnP activity was defined as the amount of enzyme required to oxidize $1 \mu \mathrm{mol}$ of $\mathrm{Mn}^{2+}$ to $\mathrm{Mn}^{3+}$ per minute.

Chemical oxygen demand (COD), total nitrogen (TN), and ammonia nitrogen were measured according to the standard $\mathrm{HACH}$ method. The $\mathrm{pH}$ values were measured using an S220 Seven Compact ${ }^{\mathrm{TM}} \mathrm{pH}$ meter (Mettler-Toledo Group, Switzerland). The supernatant obtained from the centrifugation of mixed liquid was used for the bacterial plate counting and the spread plate technique followed the standard method [21].

\section{RESULTS AND DISCUSSION}

\section{A. Optimization of Operational Conditions}

The operational mode of run/stop cycle favors the treatment performance of the bioreactor. The polyurethane foam cubes filled the basket with high porosity (the average porosity in each basket was around 60\%), good for the circulation of liquid and air flows. When the basket was rotating in the liquid medium, the liquid would flow into the basket while the air squeezed out. On the other hand, when the basket was leaving the medium surface, the liquid would flow out the basket by gravity while the air immediately filling up. Therefore, the rotation would make $P$. chrysosporium immobilized on polyurethane foam cubes experiencing the nutrient and oxygen supply regularly. After the basket rotated out of the medium surface, the free water in the pores between the carriers aggregate would flow out until only a thin layer of liquid left between biofilm and air, thus the resistance of oxygen transfer into the biofilm could be reduced significantly.

The removal efficiency for carbamazepine achieved under 5 min run/15 min stop (mode II) was approximately $20 \%$ higher compared to under $5 \mathrm{~min}$ run/5 min stop (mode I), $93.00 \pm$ $21.51 \%$ vs. $71.00 \pm 11.20 \%$. There were statistically significant differences in carbamazepine removal efficiency (0.0024) between modes I and II. A longer stop time means a longer contact time between white-rot fungus and oxygen in the air. It is well known that the lignin degradation is an oxidative process, requiring a high $\mathrm{O}_{2}$ level [16]. Since a nitrogen-limited culture medium was used in this study, in case of the excessive carbon source, the mass transfer of oxygen would be counterchecked due to the excessive extracellular amylase excreted by the white-rot fungus [22]. This problem can be solved through the application of a longer stop time since it can provide more contact between microorganism and oxygen. As a result, the enzymatic production of white-rot fungus could be improved [12] and a relatively high removal efficiency for carbamazepine was achieved.

\section{B. Bioreactor Performance}

To our best knowledge, there has been no study reporting about the PhACs removal using a white-rot fungus enhanced rotating biological contactor (RBC). Vasiliadou et al. [23] treated a synthetic wastewater spiked with four kinds of PhACs including carbamazepine by a two stages activated sludge-RBC, with the total removal efficiency for 
carbamazepine at $49.4 \%$ under 4-day HRT. In the current study, after one month of adaptation period, the removal efficiency for carbamazepine reached $>90 \%$. However, the removal efficiency decreased from Day 74 when the glucose loading in the influent was cut from 10 to $5 \mathrm{~g} / \mathrm{L}$, and on Day 75-118, the average removal efficiency for carbamazepine was $86.29 \pm 3.29 \%$. Starting from Day 118, the feeding glucose concentration further decreased from 2.5 to $1.0 \mathrm{~g} / \mathrm{L}$ and the carbamazepine removal efficiency also further declined to $75.36 \pm 10.18 \%$ (Fig. 1). This result is in a good agreement with some other studies in terms of the effect of the feeding carbon source on the contaminant removal performance through the white-rot fungus reactor. Pakshirajan and Kheria [24] found the maximum decolourization efficiency $(83 \%)$ was achieved when $10 \mathrm{~g} / \mathrm{L}$ of glucose was used in the media through an RBC treating the textile wastewater. The system performed poorly in decolorizing the wastewater without any supplementation of carbon source. The decolourization efficiency was poor when the media contained glucose at concentration $<5 \mathrm{~g} / \mathrm{L}$. Blanquez et al. [25] also found the decolourization efficiency dropped from around 70 to $60 \%$ when the feeding glucose concentration was cut from 3 to $2 \mathrm{~g} / \mathrm{L}$ through a Trametes versicolor enhanced $\mathrm{RBC}$ for treating the textile wastewater.

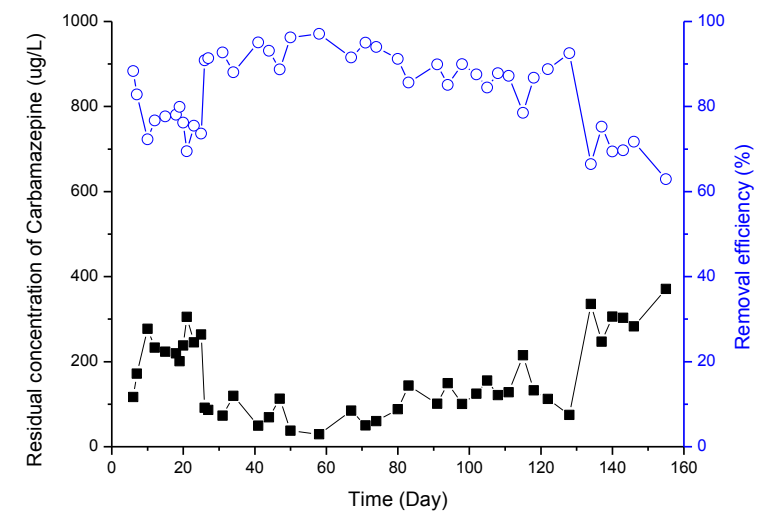

Fig. 1. The residual concentrations of carbamazepine (- $\square$-) and the corresponding removal efficiencies (- $\bigcirc-)$ using the rotating basket contactor reactor in a continuous operation.

After one month of fungal adaptation, the COD removal efficiency reached $85 \%$ and remained at this level even when the concentration of the feeding carbon source was gradually reduced. During the periods of Day 31-74, Day 75-118, and Day 119-160, the average COD removal efficiencies were 86.51, 84.38, and 86.47\%, respectively (Fig. 2).

On the other hand, there was a completely different performance occurred in case of the TN removal. During the first month, TN was almost completely removed (removal efficiencies $>95 \%$ ) and after that, it began to gradually decline. The average residual TN concentration was 36.23, 280.50, and $140.64 \mathrm{mg} / \mathrm{L}$, respectively, during Day 31-74, Day 75-118, and Day 119-160. This phenomenon has also been observed in other studies. Cruz-Morato et al. [26] found the concentration of ammonium nitrogen increased under the nutrient scarcity condition in a batch fluidized bed reactor inoculated with $T$. versicolor. Zhang and Geißen [27] also observed the nitrogen accumulation in the degradation of carbamazepine and attributed to the lysis of fungal mycelia under starvation conditions.

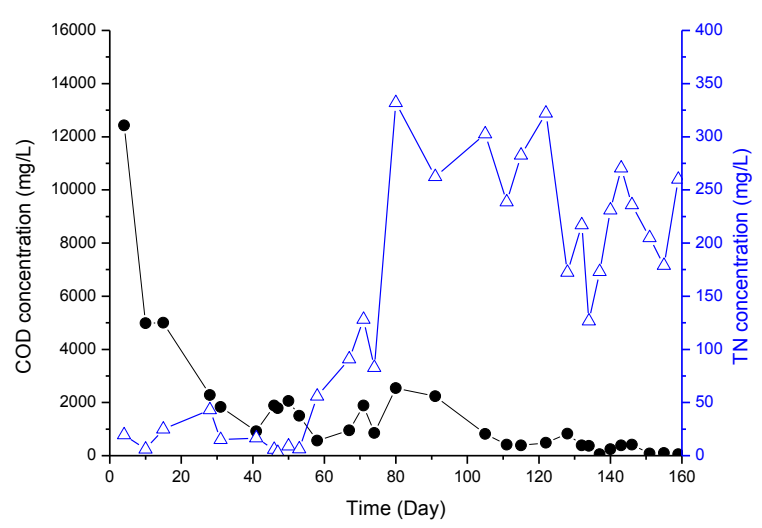

Fig. 2. The variation of the residual concentrations of COD (--) and $\mathrm{TN}(-\Delta-)$ in the reactor effluent.

There was a gradual decline in $\mathrm{pH}$ value of the effluent before Day 74, dropping from nearly 4.0 to around 2.5 , and then increased slowly. The average $\mathrm{pH}$ values were 4.6 and 6.2 during the periods of Day 75-118 and Day 119-160, respectively. The activity of the extracellular enzyme remained at a relatively low level during the whole period. The detected activity of MnP was always $\leq 3.5 \mathrm{U} / \mathrm{L}$. The low activity of enzymes was also observed by other studies in terms of operating the continuous white-rot fungus reactor under non-sterile conditions [24, 27, 28]. In addition, the bacterial counting also showed the viable bacterial number was continuously decreased to $<2.0 \times 10^{6} \mathrm{CFUs} / \mathrm{mL}$ during the reactor operation under non-sterile conditions.

\section{CONCLUSION}

A rotating basket contactor reactor immobilized with $P$. chrysosporium on the polyurethane foam cubes $(1.0 \times 1.0 \times 1.0$ $\mathrm{cm}^{3}$ ) was continuously operated for around 160 days under the non-sterile condition, to remove carbamazepine from a synthetic wastewater. More than $90 \%$ removal efficiency was achieved with the glucose addition $(10 \mathrm{~g} / \mathrm{L})$ into the influent as the external carbon source, with the 5 min run/15 min stop operational mode. The removal efficiency dropped about $15 \%$ when the glucose loading was gradually reduced to $1 \mathrm{~g} / \mathrm{L}$.

\section{ACKNOWLEDGMENT}

This study was supported by the University of Macau Multi-Year Research Grant (MYRG2014-00112-FST) and by grants from the Macau Science and Technology Development Fund (FDCT/061/2013/A2, FDCT/063/2013/A2).

\section{REFERENCES}

[1] N. Luong, F.I. Hai, S. Yang, J. Kang, F. Leusch, F. Roddick, W.E. Price, L.D. Nghiem, "Removal of pharmaceuticals, steroid hormones, phytoestrogens, UV-filters, industrial chemicals and pesticides by 
Trametes versicolor: role of biosorption and biodegradation," Int. Biodeter. Biodegr., vol. 88, pp. 169-175, Mar. 2014.

http://dx.doi.org/10.1016/j.ibiod.2013.12.017

[2] A. Joss, S. Zabczynski, A. Göbel, B. Hoffmann, D. Löffler, C. McArdell, T. Ternes, T. Thomsen, H. Siegrist, "Biological degradation of pharmaceuticals in municipal wastewater treatment: Proposing a classification scheme," Water Res., vol. 40, pp. 1686-1696, May 2006. http://dx.doi.org/10.1016/j.watres.2006.02.014

[3] T.A. Ternes, N. Herrmann, M. Bonerz, T. Knacker, H. Siegrist, A. Adriano Joss, "A rapid method to measure the solid-water distribution coefficient $\left(\mathrm{K}_{\mathrm{d}}\right)$ for pharmaceuticals and musk fragrances in sewage sludge," Water Res., vol. 38, pp. 4075-4084, Nov. 2004.

http://dx.doi.org/10.1016/j.watres.2004.07.015

[4] Y. Zhang, S. Geißen, C. Gal, "Carbamazepine and diclofenac: removal in wastewater treatment plants and occurrence in water bodies," Chemosphere, vol. 73, pp. 1151-1161, Nov. 2008. http://dx.doi.org/10.1016/j.chemosphere.2008.07.086

[5] Y. Luo, W. Guo, H.H. Ngo, L.D. Nghiem, F.I. Hai, J. Zhang, S. Liang, X.C. Wang, "A review on the occurrence of micropollutants in the aquatic environment and their fate and removal during wastewater treatment," Sci. Total Environ., vol. 473-474, pp. 619-641, Mar. 2014. http://dx.doi.org/10.1016/j.scitotenv.2013.12.065

[6] C.G. Daughton, T.A. Ternes, "Pharmaceuticals and Personal Care Products in the Environment: Agents of Subtle Change?," Environ. Health Perspect., vol. 107, pp. 907-938, Dec. 1999.

http://dx.doi.org/10.1289/ehp.99107s6907

[7] T. Kosjek, H.R. Andersen, B. Kompare, A. Ledin, E. Heath, "Fate of carbamazepine during water treatment," Environ. Sci. Technol., vol. 43, pp. 6256-6261, Jul. 2009. http://dx.doi.org/10.1021/es900070h

[8] P. Westerhoff, H. Moon, D. Minakata, J. Crittenden, "Oxidation of organics in retentates from reverse osmosis wastewater reuse facilities," Water Res., vol. 43, pp. 3992-3998, Sep. 2009 http://dx.doi.org/10.1016/j.watres.2009.04.010

[9] D. Bathen, "Physical waves in adsorption technology—an overview," Sep. Purif. Technol., vol. 33, pp. 163-177, Oct. 2003. http://dx.doi.org/10.1016/S1383-5866(03)00004-2

[10] A.P. Singh, T. Singh, "Biotechnological applications of wood-rotting fungi: A review," Biomass Bioenerg., vol. 62, pp. 198-206, Mar. 2014. http://dx.doi.org/10.1016/j.biombioe.2013.12.013

[11] A. Jelic, C. Cruz-Morató, E. Marco-Urrea, M. Sarrà, S. Perez, T. Vicent, M. Petrović, D. Barcelo, "Degradation of carbamazepine by Trametes versicolor in an air pulsed fluidized bed bioreactor and identification of intermediates," Water Res., vol. 46, pp. 955-964, Mar. 2012. http://dx.doi.org/10.1016/j.watres.2011.11.063

[12] Rodarte-Morales, G. Feijoo, M. Moreira, J. Lema, "Operation of stirred tank reactors (STRs) and fixed-bed reactors (FBRs) with free and immobilized Phanerochaete chrysosporium for the continuous removal of pharmaceutical compounds," Biochem. Eng. J., vol. 66, pp. 38-45, Jul. 2012.

http://dx.doi.org/10.1016/j.bej.2012.04.011

[13] L. Nguyen, F.I. Hai, S.Yang, J. Kang, F. Leusch, F. Roddick, W. Price, L. Nghiem, "Removal of trace organic contaminants by an MBR comprising a mixed culture of bacteria and white-rot fungi," Bioresour. Technol., vol. 148, pp. 234-241, Nov. 2013. http://dx.doi.org/10.1016/j.biortech.2013.08.142

[14] S. Sankaran, S.K. Khanal, N. Jasti, B. Jin, A.L. Pometto III, J.H. Van Leeuwen, "Use of Filamentous Fungi for Wastewater Treatment and Production of High Value Fungal Byproducts: A Review," Crit. Rev. Env. Sci. Technol., vol. 40, pp. 400-449, Apr. 2010. http://dx.doi.org/10.1080/10643380802278943

[15] T. Kirk, W. Connors, J. Zeikus, "Requirement for a growth substrate during lignin decomposition by two wood-rotting fungi," Appl. Environ. Microbiol., vol. 32, pp. 192-194, Jul. 1976.

[16] T. Kirk, E. Schultz, W. Connors, L. Lorenz, J. Zeikus, "Influence of culture parameters on lignin metabolism by Phanerochaete chrysosporium," Arch. Microbiol., vol. 117, pp. 277-285, Jun. 1978. http://dx.doi.org/10.1007/BF00738547

[17] M. Leisola, D. Ulmer, A. Fiechter, "Problem of oxygen transfer during degradation of lignin by Phanerochaete chrysosporium," Eur. J. Appl. Microbiol. Biotechnol., vol. 17, pp. 113-116, Mar. 1983. http://dx.doi.org/10.1007/BF00499861

[18] S.R. Couto, "Dye removal by immobilised fungi," Biotechnol. Adv., vol. 27, pp. 227-235, May-Jun. 2009. http://dx.doi.org/10.1016/j.biotechadv.2008.12.001
[19] V.S. More, P.N. Tallur, F.N. Niyonzima, S.S. More, "Enhanced degradation of pendimenthalin by immobilized cells of Bacillus lehensis XJU," 3 Biotech., In press, Apr. 2015.

[20] M. Tien, T.K. Kirk, "Lignin Peroxidase of Phanerochaete chrysosporium," Methods Enzymol., vol. 161, pp. 238-249, Aug. 1988. http://dx.doi.org/10.1016/0076-6879(88)61025-1

[21] A.D. Eaton, A.H. Franson, Standard methods for the examination of water and wastewater. American Pubic Health Association/American Water Works Association/Water Environment Federation, Washington: D.C., 2005, 1368 p.

[22] D. Gao, Y. Zeng, X.Wen, Y. Qian, "Competition strategies for the incubation of white rot fungi under non-sterile conditions," Process Biochem., vol. 43, pp. 937-944, Sep. 2008. http://dx.doi.org/10.1016/j.procbio.2008.04.026

[23] I.A. Vasiliadou, R. Molina, F. Martínez, J.A. Melero, "Experimental and modeling study on removal of pharmaceutically active compounds in rotating biological contactors," J. Hazard. Mater., vol. 274, pp. 473-482, Jun. 2014. http://dx.doi.org/10.1016/j.jhazmat.2014.04.034

[24] K. Pakshirajan, S. Kheria, "Continuous treatment of coloured industry wastewater using immobilized Phanerochaete chrysosporium in a rotating biological contactor reactor," J. Environ. Manage., vol. 101, pp. 118-123, Jun. 012.

[25] P. Blánquez, M. Sarrà, T. Vicent, "Development of a continuous process to adapt the textile wastewater treatment by fungi to industrial conditions," Process Biochem., vol. 43, pp. 1-7, Jan. 2008. http://dx.doi.org/10.1016/j.procbio.2007.10.002

[26] L. Cruz-Morató, S. Ferrando-Climent, D. Rodriguez-Mozaz, E. Barceló, T. Marco-Urrea, T. Vicent, M. Sarrà, "Degradation of pharmaceuticals in non-sterile urban wastewater by Trametes versicolor in a fluidized bed bioreactor," Water Res., vol. 47, pp. 5200-5210, Sep. 2013. http://dx.doi.org/10.1016/j.watres.2013.06.007

[27] Y. Zhang, S. Geißen, "Elimination of carbamazepine in a non-sterile fungal bioreactor," Bioresour. Technol., vol. 112, pp. 221-227, May 2012 . http://dx.doi.org/10.1016/j.biortech.2012.02.073

[28] J. Śíma, J. Pocedič, T. Roubíčková, P. Hasal, "Rotating drum biological contactor and its application for textile dyes decolourization," Procedia Eng., vol. 42, pp. 1579-1586, Aug. 2012.

http://dx.doi.org/10.1016/j.proeng.2012.07.551 